Original article

\title{
Effect of preconception counseling on health promoting behaviors of reproductive age women in Sari city
}

\author{
Marzieh Shabani $^{1}$, Saeed Omidi ${ }^{*}$, Rabiallah Farmanbar ${ }^{3}$, Zeinab Hamzegardeshi ${ }^{4}$
}

(Receive: 20 Dec 2015; Accept: 10 Feb 2016)

\begin{abstract}
Background and Purpose: Prenatal health behaviors encompass different health-promoting behaviors in women of reproductive age, which improve physical and mental health, as well as pregnancy outcomes. This study aimed to evaluate the effect of prenatal training on the health-promoting behaviors of the women of reproductive age.

Materials and Methods: This randomized controlled clinical trial was conducted on 104 women of reproductive age in Sari city located in Mazandaran, Iran. Subjects were randomly divided into two groups of intervention and control. Inclusion criteria were willingness to have children, age range of 18-40 years, and overall physical and mental health. Data were collected using sociodemographic questionnaires and standard health promoting lifestyle (HPLP-II) questionnaire. In the intervention group, training was performed in four sessions (45-60 minutes) at one-week intervals focusing on health responsibility, physical activity and stress management. One month after the intervention, data analysis was performed using independent T-test, Mann-Whitney U test, Kruskal-Wallis test, Chisquare test, and mean, frequency, and standard deviation.

Results: After prenatal training, total score of health-promoting behaviors had a significant difference in the intervention and control group (151.60 \pm 17.503 vs. $139.42 \pm 19.596)(P=0.002)$. Mean score of health responsibility (27.75 \pm 4.066$)$, physical activity $(21.10 \pm 3.211)$ and stress management (23.19 \pm 3.036$)$ were higher in the intervention group compared to the control group (23.90 $\pm 5.032,16.84 \pm 4.017$ and 19.66 \pm 3.330 , respectively), and the study groups had a statistically significant difference in this regard $(P<0.001)$.

Conclusion: According to the results of this study, prenatal training could enhance health-promoting behaviors in women of reproductive age. Therefore, it is recommended that consultation and training sessions be considered during prenatal care.
\end{abstract}

Keywords: Health promotion, Health-promoting behaviors, Prenatal training, Reproductive age

\section{Introduction}

Health and well-being of women is essential to the progress of every society, and poor maternal health is considered a major risk factor for complications such as premature birth, low birth weight, and infant mortality (1). Energy and mobility in the family largely influence the health of women, the positive outcomes of which are reflected in the community (2).

Women account for $50 \%$ of the population in a society; as such, promoting the health of women is a primary goal in health programs and care policies (3). According to the World Health Organization (WHO), maternal mortality associated with pregnancy and childbirth is estimated at 500,000 cases per year (4), which is approximately one death per minute $(3,5)$. Given the importance of maternal health promotion and reduction of adverse birth outcomes, several researchers, physicians and policy-makers have been more concerned with the

\footnotetext{
${ }^{1}$ School of Health, Guilan University of Medical Sciences, Rasht, Iran

2,* Corresponding author: School of Health, Guilan University of Medical Sciences, Rasht, Iran.

Email: s_omidi2000@yahoo.com

${ }^{3}$ Departement of Health Education and Health Promotion, School of Health, Guilan University of Medical Sciences, Rasht, Iran

${ }^{4}$ Departement of Reproductive Health, Nasibeh School of Nursing \& Midwifery, Mazandaran University of Medical Sciences, Sari, Iran
} 
health education of women before pregnancy rather than during the prenatal period.

Prenatal health behaviors encompass various health behaviors in the women of reproductive age, which are applied to improve physical and mental conditions, as well as pregnancy outcomes (6). In 1991, the Center of Disease Control and Prevention in the U.S. announced that the mortality rate among the women who did not receive midwifery care was 6.5 times higher than those receiving adequate care and support during the postpartum period. Despite proper midwifery care, numerous studies have attributed adverse pregnancy and childbirth outcomes to lack of prenatal consultation and care (7).

Prenatal care is referred to the healthcare services implemented to evaluate and predict the possible risks of pregnancy and childbirth. By offering relevant training and providing diagnostic and therapeutic proceedings, as well as medical interventions, these services lead to the improvement of maternal and fetal health (8-10). Identification of risk factors, such as drug and alcohol abuse and radiation exposure, in prenatal consultation plays a pivotal role in the prevention of these factors during pregnancy $(11,12)$.

Most of the studies conducted in this regard have focused on the effects of prenatal care on the management of chronic maternal diseases, controlling diabetes and folic acid consumption; as such, prenatal health promotion has been rarely discussed in the literature (6). For instance, a study was performed in the U.S. during 20042008 to evaluate the relationship between prenatal consultation and maternal behaviors before and after pregnancy. According to the findings, prenatal consultation was significantly associated with alcohol rehabilitation within three months before pregnancy. Moreover, researchers denoted a significant correlation between prenatal consultation and daily use of multivitamins by women within one month before pregnancy (13).

Another study was conducted in the Netherlands to assess the effects of prenatal consultation on the lifestyle and other behaviors of women before and during pregnancy. According to the results, after prenatal consultation, a higher percentage of women started folic acid consumption before pregnancy and reduced alcohol consumption during the first trimester of pregnancy. In addition, a significant proportion of the studied women changed their behaviors in order to diminish adverse pregnancy outcomes (14).

This study aimed to evaluate the effects of prenatal training on the health-promoting behaviors of women of reproductive age in different healthcare centers. It is hoped the findings of this study lay the foundation for the promotion of maternal and neonatal health as the two vulnerable populations of society.

\section{Materials and Methods}

This randomized controlled trial (IRCT 2016030226879 N1) was conducted to evaluate the effects of prenatal training on the health-promoting behaviors of women of reproductive age in the healthcare centers of Sari city located in Mazandaran province, Iran in 2015. Sample size was determined based on the data of a study performed to assess the effects of designated training interventions on the health-promoting behaviors of menopausal women using the individual empowerment model (15). In the mentioned study, total mean score of behavior in the experimental group was $37.3 \pm 10.16$, while it was determined at $31.95 \pm 7.43$ in the control group.

In our study, with a $95 \%$ confidence interval and $90 \%$ test power, 43 subjects were determined for each group. Considering a 20\% sample loss, 52 participants were allocated to each of the study groups. Inclusion criteria were as follows: 1) women of reproductive age; 2) age range of 18-40 years; 3 ) overall physical and mental health (no history of systematic diseases or medication use for underlying diseases); 4) lack of psychological disorders and drug abuse; 5) written informed consent for participation; 6) basic literacy; 7) residence in Sari city and 8) having adequate time for completing the questionnaires and participation in the study. Women who were not willing to participate or planned to move from Sari city were excluded from the study.

After obtaining the required permit, subjects were selected via multistage sampling. Out of 21 health 
centers in Sari, two centers that were homogenous in terms of socioeconomic variables were selected for this study. To keep the control subjects blinded from the proceedings of the intervention, these health centers were selected from two different areas of the city. Using random allocation, one of the health centers was determined as the intervention setting, while the other one was considered as control. Finally, study samples were randomly selected based on the available records of women who were willing to have a child.

Study protocol was approved by the Ethics Committee of Guilan University of Medical Sciences, and after obtaining the required permit from the authorities, written informed consent was provided from all the participants. Consent forms were distributed among the women during the first meeting session (introduction). Following the collection of the consent forms and selection of the research units, questionnaires were completed by the women during the second session.

Data were collected using sociodemographic questionnaires consisting of 15 items, including personal information (age, education level, employment status, sufficiency of family income, age at first marriage, height and weight), pregnancy history (age at first pregnancy, gravidity and parity, and number of abortions), and the age, education level and occupational status of the spouse. In addition, body mass index of the subjects was calculated based on height and weight and categorized into four groups in accordance with the classification of WHO, as follows: $<18.5,18.5-24.9,25-29.9$, and $\geq 30 \mathrm{~kg} / \mathrm{m}^{2}$.

Another data collection tool used in this study was the health promoting lifestyle (HPLP-II) questionnaire, which was developed by Walkers et al. in 1987 based on Pender's model for health-promoting behaviors, which provides the multidimensional assessment of health-promoting behaviors. HPLP-II measures the frequency of applying health-promoting behaviors in six dimensions of health responsibility, physical activity, nutrition, spiritual growth, stress management, and interpersonal relations (52 items). Items in this scale are responded with options of never (score 1), sometimes (score 2), usually (score 3 ), and always (score 4) within a score range of 52208. Each dimension in HPLP-II could be scored independently.

Validity and reliability of the Persian version of HPLP-II were confirmed in a study by Mohammadi Zeidi et al. in 2011 at the Cronbach's alpha of 82\% and interclass correlation-coefficient of $91 \%$ (16).

In this study, we calculated the maximum and minimum scores of each dimension of HPLP-II, as well as the mean score of each dimension. If the participants achieved mean scores of equal or lower than the average level in any dimension of health-promoting behaviors, those dimensions were considered as the training needs of the study groups. In this study, HPLP-II dimensions of physical activity and stress management had lower scores (below average), and score of health responsibility was almost equal to the average level. Therefore, these aspects were considered as the most significant training needs of the participants.

Women who were willing to have a child were divided into 8 groups of 5 and 2 groups of 6 . For the training of the women in the intervention group, pamphlets and educational packages were provided by the researcher. As presented in Framework 1, the intervention in this study included four training sessions (45-60 minutes) for the intervention control groups, which were held once a week. Training sessions consisted of question and answer, group discussion, and related lectures. One month after the intervention, women of reproductive age in the intervention and control groups completed the HPLPII questionnaire again.

Data analysis was performed in SPSS V.20. Data of each stage of the study were collected and codified, and normal distribution of data was evaluated using the Kolmogorov-Smirnov test. In addition, we used descriptive statistics (mean, frequency, percentage, and standard deviation) and parametric and nonparametric tests (independent and paired T-test, Mann-Whitney U test, Kruskal-Wallis test, Chi-square test, Fisher's exact test, ANOVA, and Wilcoxon test). In this study, $\mathrm{P}$ value of less than 0.05 was considered significant.

In order to observe the ethical considerations, the contents of educational packages were presented to the participants of the control group after the secondary evaluation. 
Framework 1. Educational package of healthpromoting behaviors for women of reproductive age

\section{Session one}

Presenting the definition of health and health promotion/introducing the questionnaire of healthpromoting lifestyle (HPLP-II)

Explanation on the importance and necessity of health-promoting behavior training

\section{Session two}

Definition of health responsibility

Tips on obtaining information from specialists about proper self-care and information to better understand the provided instructions

Asking for training or guidance/discussion with other participants about problems and concerns/ reporting unusual signs of disease to physicians or other healthcare personnel

\section{Session three}

Introduction to physical activity, different types of sports and stretching exercises

Benefits of exercise, location of physical activity, and time of exercise

\section{Session four}

- Positive and negative forms of stress

- Sources of stress and reaction of body to stress (physical, psychological and behavioral effects)

- Stress management and the ability to cope with stress

- Coping strategies in stressful situations

- Intellectual solutions to cope with stress

\section{Results}

In this study, we evaluated 48 women in the intervention group (three cases became pregnant and one case moved from Sari city) and 50 women

Table 1. Comparison of demographic variables in reproductive women referring to Sari health centers in intervention and control groups

\begin{tabular}{|c|c|c|c|c|c|}
\hline \multirow{2}{*}{ Variable } & \multicolumn{2}{|c|}{ Intervention group } & \multicolumn{2}{|c|}{ Control group } & \multirow{2}{*}{$P$-value } \\
\hline & Mean & Standard deviation & Mean & Standard deviation & \\
\hline Age (years) & 28.17 & 5.593 & 27.65 & 5.324 & 0.629 \\
\hline Age of spouse & 31.77 & 6.141 & 31.58 & 4.775 & 0.859 \\
\hline Age at first marriage & 20.98 & 4.007 & 19.98 & 3.734 & 0.191 \\
\hline \multirow[t]{2}{*}{ Age at first pregnancy } & 23.06 & 3.801 & 22.34 & 4.546 & 0.505 \\
\hline & $\mathrm{N}$ & $\%$ & $\mathrm{~N}$ & $\%$ & \\
\hline $\begin{array}{l}\text { Body mass index } \\
\left(\mathrm{kg} / \mathrm{m}^{2}\right) \\
24.9-18.5 \\
29.9-25 \\
30 \geq\end{array}$ & $\begin{array}{l}14 \\
22 \\
16\end{array}$ & $\begin{array}{l}26.9 \\
42.3 \\
30.8\end{array}$ & $\begin{array}{l}15 \\
27 \\
10\end{array}$ & $\begin{array}{l}28.8 \\
51.9 \\
19.2\end{array}$ & 0.381 \\
\hline $\begin{array}{l}\text { Occupation status } \\
\text { Housewife } \\
\text { Employee }\end{array}$ & $\begin{array}{c}48 \\
4\end{array}$ & $\begin{array}{c}92.3 \\
7.7\end{array}$ & $\begin{array}{c}49 \\
3 \\
\end{array}$ & $\begin{array}{c}94.2 \\
5.8\end{array}$ & 0.696 \\
\hline $\begin{array}{l}\text { Education status } \\
\text { Primary } \\
\text { Secondary } \\
\text { High school } \\
\text { diploma } \\
\text { Academic }\end{array}$ & $\begin{array}{c}1 \\
6 \\
6 \\
28 \\
11\end{array}$ & $\begin{array}{c}1.9 \\
11.5 \\
11.5 \\
53.9 \\
21.2\end{array}$ & $\begin{array}{c}3 \\
10 \\
2 \\
24 \\
13\end{array}$ & $\begin{array}{c}5.8 \\
19.2 \\
3.9 \\
46.1 \\
25\end{array}$ & 0.382 \\
\hline $\begin{array}{l}\text { Parity } \\
0 \\
1 \\
2\end{array}$ & $\begin{array}{c}25 \\
22 \\
5\end{array}$ & $\begin{array}{c}48.1 \\
42.3 \\
9.6\end{array}$ & $\begin{array}{c}25 \\
27 \\
0\end{array}$ & $\begin{array}{c}48.1 \\
51.9 \\
0\end{array}$ & 0.064 \\
\hline $\begin{array}{l}\text { Number of abortions } \\
0 \\
1\end{array}$ & $\begin{array}{l}36 \\
16\end{array}$ & $\begin{array}{l}69.2 \\
30.8\end{array}$ & $\begin{array}{c}45 \\
7\end{array}$ & $\begin{array}{l}86.5 \\
13.5\end{array}$ & 0.033 \\
\hline $\begin{array}{l}\text { Family income status } \\
\text { Not sufficient } \\
\text { Almost sufficient } \\
\text { Sufficient }\end{array}$ & $\begin{array}{c}6 \\
43 \\
3\end{array}$ & $\begin{array}{c}11.5 \\
82.7 \\
5.8\end{array}$ & $\begin{array}{c}1 \\
43 \\
8\end{array}$ & $\begin{array}{c}1.9 \\
82.7 \\
15.4\end{array}$ & 0.054 \\
\hline
\end{tabular}


Table 2. Mean scores of different dimensions of health-promoting behaviors in intervention and control groups before and after prenatal training

\begin{tabular}{|c|c|c|c|c|c|c|}
\hline \multirow{2}{*}{ Dimension } & & \multicolumn{2}{|c|}{ Intervention group } & \multicolumn{2}{|c|}{ Control group } & \multirow{2}{*}{$P$-value } \\
\hline & & Mean & Standard deviation & Mean & Standard deviation & \\
\hline \multirow[t]{2}{*}{ Health responsibility } & Before intervention & 22.88 & 5.462 & 22.56 & 4.599 & 0.742 \\
\hline & After intervention & 27.75 & 4.066 & 23.90 & 5.032 & 0.000 \\
\hline \multirow[t]{2}{*}{ Physical activity } & Before intervention & 14.62 & 4.516 & 16.90 & 3.706 & 0.006 \\
\hline & After intervention & 21.10 & 3.211 & 16.84 & 4.017 & 0.000 \\
\hline \multirow{2}{*}{ Nutrition } & Before intervention & 23.19 & 4.270 & 23.50 & 4.300 & 0.715 \\
\hline & After intervention & 24.54 & 4.232 & 24.34 & 5.009 & 0.830 \\
\hline \multirow{2}{*}{ Spiritual growth } & Before intervention & 26.79 & 6.461 & 27.58 & 4.160 & 0.461 \\
\hline & After intervention & 34.00 & 44.079 & 27.52 & 4.564 & 0.503 \\
\hline \multirow{2}{*}{ Interpersonal relations } & Before intervention & 26.02 & 5.995 & 26.42 & 4.960 & 0.709 \\
\hline & After intervention & 27.27 & 4.819 & 27.16 & 4.871 & 0.910 \\
\hline \multirow{2}{*}{ Stress management } & Before intervention & 19.44 & 4.763 & 19.29 & 2.858 & 0.842 \\
\hline & After intervention & 23.19 & 3.036 & 19.66 & 3.330 & 0.000 \\
\hline \multirow{2}{*}{ Total } & Before intervention & 132.37 & 23.340 & 136.25 & 16.942 & 0.334 \\
\hline & After intervention & 151.60 & 17.503 & 139.42 & 19.596 & 0.002 \\
\hline
\end{tabular}

in the control group (two cases became pregnant). Comparison in terms of normally distributed demographic variables and categorical variables of the women of reproductive age referring to the health centers of Sari is presented in Table 1.

According to the information in Table 2, mean score of physical activity had a significant difference between the intervention and control groups before training, so that the score of this health-promoting dimension was higher in women of the control group compared to the intervention group. On the other hand, no significant differences were observed in the mean scores of other dimensions of healthpromoting behaviors between the two groups.

Before the training sessions, women in the intervention and control groups achieved the lowest score in the dimension of physical activity, while the highest score was obtained in the dimension of spiritual growth. Other dimensions of healthpromoting behaviors in order of the highest to lowest scores were interpersonal relations, nutrition, health responsibility, and stress management.

Distribution of the mean scores of different HPLPII dimensions in the intervention and control groups is shown in Table 2. According to the information in this table, mean scores of health responsibility, physical activity and stress management in the two groups had a significant difference after prenatal training. Moreover, total mean score of healthpromoting behaviors had a significant difference between the two groups, so that the total score of intervention group was higher compared to the control group.

According to the results of this study, mean scores

Table 3. Mean scores of health-promoting lifestyle before and after prenatal training in intervention and control groups

\begin{tabular}{|c|c|c|c|c|c|c|}
\hline \multirow{2}{*}{ Dimension } & & \multicolumn{2}{|c|}{ Before intervention } & \multicolumn{2}{|c|}{ After intervention } & \multirow{2}{*}{$P$-Value } \\
\hline & & Mean & Standard deviation & Mean & Standard deviation & \\
\hline \multirow{2}{*}{ Health responsibility } & Intervention group & 22.94 & 5.525 & 27.75 & 4.066 & \multirow{2}{*}{$0.0001>0.129$} \\
\hline & Control group & 22.60 & 4.634 & 23.90 & 5.032 & \\
\hline \multirow{2}{*}{ Physical activity } & Intervention group & 14.42 & 4.361 & 21.10 & 3.211 & \multirow{2}{*}{$\begin{array}{c}0.0001> \\
0.961\end{array}$} \\
\hline & Control group & 16.80 & 3.709 & 16.84 & 4.017 & \\
\hline \multirow{2}{*}{ Nutrition } & Intervention group & 22.96 & 4.131 & 24.54 & 4.232 & 0.044 \\
\hline & Control group & 23.42 & 4.338 & 24.34 & 5.009 & 0.329 \\
\hline \multirow{2}{*}{ Spiritual growth } & Intervention group & 26.79 & 6.461 & 34.00 & 44.079 & 0.483 \\
\hline & Control group & 27.56 & 4.166 & 27.52 & 4.564 & 0.962 \\
\hline \multirow{2}{*}{ Interpersonal relations } & Intervention group & 25.85 & 6.130 & 27.27 & 4.819 & 0.116 \\
\hline & Control group & 26.40 & 4.957 & 27.16 & 4.871 & 0.411 \\
\hline \multirow{2}{*}{ Stress management } & Intervention group & 19.44 & 4.744 & 23.19 & 3.036 & \multirow{2}{*}{$\begin{array}{c}0.0001> \\
0.577\end{array}$} \\
\hline & Control group & 19.30 & 2.887 & 19.66 & 3.330 & \\
\hline \multirow{2}{*}{ Total } & Intervention group & 132.42 & 23.929 & 151.60 & 17.503 & \multirow{2}{*}{$\begin{array}{c}0.0001> \\
0.328\end{array}$} \\
\hline & Control group & 136.08 & 16.806 & 139.42 & 19.596 & \\
\hline
\end{tabular}


of the dimensions of health responsibility, physical activity, stress management and nutrition, as well as the total mean score of health-promoting behaviors, increased after training in the intervention group, which was indicative of significant differences in this regard before and after prenatal training (Table $3)$. However, according to the information in Table 3 , no such difference was observed in women of the control group.

\section{Discussion}

According to the results of the present study, women in the intervention and control groups had the lowest score in the dimension of physical activity before training, while the highest score was obtained in the dimension of spiritual growth. Other dimensions of health-promoting behaviors in order of the highest to lowest scores were interpersonal relations, nutrition, health responsibility, and stress management. Status of the highest and lowest scores was similar in both groups after the intervention, and other dimensions in order of the highest to lowest scores were health responsibility, interpersonal relations, nutrition, and stress management.

In another study conducted to survey the dimensions of prenatal lifestyle in Gonabad city (Iran), physical activity and stress management accounted for the lowest scores (1). Furthermore, the results of another research performed in 2014 on the high school students of district two of Isfahan city (Iran), the highest score was reported in the dimension of spiritual growth, while physical activity accounted for the lowest score of healthpromoting behaviors (17).

Similarly, in another study in this regard, health-promoting behaviors were reported to be associated with the level of anxiety and some of the demographic features of the students of Alborz University of Medical Sciences in Tehran, Iran. In addition, the lowest score was obtained in the dimension of physical activity, while the highest score was reported in the dimension of spiritual growth. According to the findings of the mentioned study, students who lived with their family achieved lower scores in the dimensions of stress management and interpersonal relations. Therefore, it could be inferred that independence from family is associated with more efficient interpersonal communications and emotional management (18).

In this regard, a research was conducted on 440 students at Yazd University of Medical Sciences (Iran), and the lowest score of health-promoting behaviors was reported in the aspect of physical activity, while spiritual growth accounted for the highest score among the students. Furthermore, the researchers claimed that male students were more inclined toward physical exercise compared to female students (19). According to the findings of another research in Turkey conducted to evaluate the relationship between health-promoting behaviors and quality of life, spiritual growth accounted for the highest score, while the lowest score was reported in the dimension of physical activity (20).

Several studies have proposed that physical exercise has not merged into the daily life of women, which might be due to factors such as lack of time, difficult career, extra responsibilities, management of household tasks, lack of suitable environment for physical activity, and insufficient access to sports services. On the other hand, advancement of technology and availability of modern facilities have pushed individuals toward sedentary lifestyle.

Women have numerous responsibilities at home, which may restrict them from improving their physical and mental health. Moreover, multiple roles of women in society expose them to higher stress, which might be the main cause of the low scores of health responsibility as observed in the present study. According to our findings and similar studies in this regard, women are in critical need of proper training on stress management in order to maintain balance between work and recreation. This helps women to prevent stressful conditions and emotional pressures they are faced with in everyday life.

As mentioned earlier, the highest score of health-promoting behaviors was observed in the dimension of spiritual growth, which is similar to previous studies in this regard. This finding could be attributed to the domination of the Islamic culture in our country. Religious beliefs and orientation of 
Iranian people advocate a purposeful life by relying on powerful divine forces so as to stay on the constructive path of growth and change.

In the present study, before prenatal training, dimensions of nutrition, spiritual growth and interpersonal relations were above the average level in the women of the intervention group, while dimensions of physical activity and stress management were below average, and the health responsibility dimension was at a moderate level. In a study conducted to examine the relationship between health-promoting behaviors and family features of high school students, spiritual growth and interpersonal relations were reported to be above the average level, while physical activity and stress management were below average. This is in congruence with the results of the current study. However, in the mentioned study, dimension of nutrition status was at a moderate level, and health responsibility was reported to be below the average level, which is inconsistent with our findings. This difference could be due to the lower age range of high school students and common stress of university entrance exam among these students.

In the current study, out of six aspects of healthpromoting behaviors, the highest score was obtained in spiritual growth, whereas the lowest score was achieved in physical activity. This finding is in line with the results of previous studies conducted on the students of Alborz University of Medical Sciences (18), another study performed in Saqez city (Iran) (21), and one research conducted on the professors of Shahid Sadoughii University of Medical Sciences in Yazd (Iran) (22).

According to the results of a study conducted to evaluate lifestyle during pregnancy in Gonabad city (Iran), physical activity and stress management accounted for the lowest scores among the dimensions of health-promoting lifestyle (1). Furthermore, findings of another research performed to examine the association of health-promoting lifestyle and quality of life in Tehran city indicated that health responsibility had the highest mean score, while the lowest mean score was reported in the dimension of stress management, which is not compatible with the results of the present study (23).
This discrepancy could be due to different cultural background of the study populations.

In the current study, mean score of health responsibility significantly increased in the women of the intervention group after the prenatal training, so that a significant difference was observed between the intervention and control groups in this dimension after the training. In addition, a significant difference was observed between women of the intervention and control groups in this dimension before and after the training sessions.

In this regard, a research was conducted to evaluate the efficacy of health responsibility training on the self-confidence of male high school students in Bagh Malek city (Iran), and the results indicated that responsibility training based on Glasser's method could increase the self-confidence of subjects in the experimental group (24). Moreover, another study was performed in Shoosh city (Iran) to evaluate the effects of responsibility training on the identity crisis of female students using reality therapy, and the findings were indicative of a significant reduction of the identity crisis of subjects in the intervention group compared to the control group (25).

In the present study, mean score of physical activity had a significant difference after the intervention in both groups, so that the score of the intervention group was higher than the control group. In addition, the score of this health-promoting dimension had a statistically significant difference before and after prenatal training. However, no such difference was observed in women of the control group.

Another study in this regard was conducted on the patients admitted to Imam Khomeini Hospital of Ahvaz (Iran). According to the obtained results, there was a significant difference between the experimental and control groups in terms of physical activity score after the intervention, while this difference was not observed before the intervention (26). It is noteworthy that in the current study, we only determined the total score of physical activity, and different levels of this dimension were not considered separately in women of the intervention and control groups. Physical exercises and sport activities play a pivotal role in disease prevention and must be considered in the planning of public 
health promotion as confirmed by several studies.

According to the results of the present study, mean score of the health-promoting dimension of nutrition had no significant difference between the intervention and control groups, while the mean score of nutrition in women of the intervention group was significantly different before and after prenatal training. In a study conducted at the healthcare centers affiliated to Shiraz University of Medical Sciences (Iran) in 2010, it was stated that training is effective in the promotion of nutritional behaviors of pregnant women (2). In another research performed in the U.S., a positive correlation was reported between prenatal consultation, multivitamin consumption, and alcohol rehabilitation in prenatal women (13).

According to the findings of another study conducted on the pregnant women referred to the medical centers of Ardabil city (Iran), mean score of nutrition had a statistically significant difference after the health-promoting intervention (27). As demonstrated in different studies, prenatal training with the objective of promoting nutritional behaviors is highly recommended for women of reproductive age before pregnancy.

In the current study, mean score of stress management had a significant difference between the intervention and control groups after prenatal training, so that the score of women in the intervention group was significantly higher than the control subjects. In the intervention group, mean score of this health-promoting behavior significantly increased after prenatal training denoting a statistically significant difference before and after the educational intervention.

In this regard, a research was performed on the students of nursing and midwifery of the Islamic Azad University of Gachsaran (Iran) in order to evaluate the effect of training on stress management skills on mental health. According to the findings, training of students on stress management skills reduced the components of mental health problems in the intervention group (28). As such, it could be concluded that proper training positively influences stress management skills and mental health.

In the current study, after the presentation of training sessions to the women of the intervention group, mean total score of health-promoting lifestyle was observed to have a significant difference. Although the total mean score had no significant difference before and after prenatal training in the control group, it showed a statistically significant difference in subjects of the intervention group before and after training sessions. As such, total mean score of health-promoting lifestyle significantly increased in the intervention group after prenatal training. This finding is in line with the results of another study conducted on postmenopausal women covered by urban health centers of Zarandieh (Iran), which denoted a significant difference in the health-promoting behaviors of women during the menopause before and after the intervention (15).

In this regard, a study was conducted to evaluate the effect of health-promoting behavior training during the first six months of the postpartum period on the quality of life of nulliparous women in Shiraz (Iran). The obtained results indicated that the total score of quality of life had a significant difference in the intervention and control groups, so that the score of quality of life was higher in the intervention group compared to the control group (2). The findings of a research performed in the Netherland suggested that in comparison with women who received standard care, healthy lifestyle was more common among the women who received prenatal consultation before pregnancy. However, this difference was not statistically significant (14).

One of the limitations of the current study was the inclusion criterion of basic literacy. Since some of the samples did not meet this criterion, they were excluded from the study. Unfortunately, it is expected that this population is more vulnerable to unhealthy behaviors during pregnancy as they are not able to exploit scientific sources to enhance their knowledge and skills in terms of health-promoting behaviors and lifestyle. Another limitation of our study was the exclusion of women with underlying diseases since they also constitute a high-risk population for health-promoting behaviors in case of pregnancy and childbirth. Therefore, it is recommended that the results of the current research be applied in health promotion planning to improve 
the quality of maternal and fetal life in healthcare centers.

\section{Conclusion}

According to the results of this study, prenatal education and training could enhance healthpromoting behaviors in women of reproductive age. Considering that the improvement of maternal health is a primary healthcare goal in every society, it is suggested that healthcare providers be encouraged to teach health-promoting behaviors during prenatal care so as to enhance the overall health and quality of life of women, as well as to reduce possible complications of pregnancy and delivery, which lead to the reduction of maternal and neonatal mortality. Moreover, it is recommended that in all stages of prenatal care in healthcare centers, appropriate interventions be implemented and effective health policies be devised in order for the promotion of preventive care services.

\section{Conflicts of interest}

This research was funded by Guilan University of Medical Sciences, Rasht, Iran.

\section{Authors' contributions}

M Shabani Chapi collected data and trained the participants; S Omidi analyzed data and guided the project; R Farmanbar advisor of the development the training protocols; Z Hamzegardeshi advisor of scientific development and validated the questionnaires. All authors contributed equally to the review, revision, editing and drafting of the manuscript.

\section{Acknowledgements}

This article was extracted from a master's thesis (registration code: 1930596722) conducted on March 6, 2015. Hereby, we extend our gratitude to the Vice Chancellor of Research at Guilan University of Medical Sciences for the financial support of this study. We would also like to thank the health department of Sari city, healthcare experts, and all the participants for assisting us in this research project.

\section{References}

1. Moshki M, Bahri N, Sadegh Moghadam L. Lifestyle of pregnant women living in Gonabad (Iran). J Res Health 2012; 2(2):200-6 (Persian).

2. Ghodsbin F, Yazdani K, Jahanbin I, Keshavarzi S. The effect of education on health-promoting behaviors at the first six weeks post-delivery on the quality of life of primiparous women. Armaghane Danesh 2012; 17(4):279-88 (Persian).

3. Mohammadinia N, Rezaei MA, Samieizadetoosi T, Rostaei F. Investigating the frequency and effective factors on maternal mortality in Sistan and Baluchistan Province, Iran, 2002-2009. Iran J Obstet Gynecol Infertil 2013; 16(44):2834 (Persian).

4. Rajaei M, Zare S, Dadipour S. Determining the frequency and causes of maternal mortality in Hormozgan Province, Iran during 2005-2011. Iran J Obstet Gynecol Infertil 2014; 16(87):9-14 (Persian).

5. Nour NM. An introduction to maternal mortality. Rev Obstet Gynecol 2008; 1(2):77-81.

6. Delissaint D. Exploring the factors associated with preconception health behaviors among women of childbearing age: a naturalistic inquiry. [Dissertation]. Texas: A\&M University Health Science Center, School of Rural Public Health; 2008.

7. Ansari NM, Izadi SF. The quality of prenatal care performance on the basis of existing care standards in health centers. Koomesh 2004; 5(1-2):81-6 (Persian).

8. Shahidi S, Aghdak P, Izadi M. Effect of pre-conception care protocol on women's awareness. Iran J Med Educ 2011; 10)5):525-32 (Persian).

9. Carson MP, Ehrenthal D. Medical issues from preconception through delivery: a roadmap for the internist. Med Clin North Am 2008; 92(5):1193-225.

10. Sackey JA. The preconception office visit. UpToDate. Available at: URL: http://www.uptodate.com/contents/thepreconception-office-visit; 2009.

11. Floyd RL, Jack BW, Cefalo R, Atrash H, Mahoney J, Herron A, et al The clinical content of preconception care: alcohol, tobacco, and illicit drug exposures. Am J Obstet Gynecol 2008; 199(6 Suppl 2):S333-9.

12. Brent RL. Saving lives and changing family histories: 
appropriate counseling of pregnant women and men and women of reproductive age, concerning the risk of diagnostic radiation exposures during and before pregnancy. Am J Obstet Gynecol 2009; 200(1):4-24.

13. Williams L, Zapata LB, D’Angelo DV, Harrison L, Morrow B. Associations between preconception counseling and maternal behaviors before and during pregnancy. Matern Child Health J 2012; 16(9):1854-61.

14. Elsinga J, de Jong-Potjer LC, van der Pal-de Bruin KM, Le Cessie S, Assendelft WJ, Buitendijk SE. The effect of preconception counselling on lifestyle and other behavior before and during pregnancy. Womens Health Issues 2008; 18(6 Suppl):S117-25.

15. Karimy M. Evaluation of the effect of educational intervention based on empowerment model of health promotion behaviors on menopautic women. Daneshvar Med 2011; 18(94):63-72 (Persian).

16. Zeidi I, Hajiagha A, Zeidi B. Reliability and validity of Persian version of the health-promoting lifestyle profile. J Mazand Univ Med Sci 2012; 22(1):S103 (Persian).

17. Tavakoli N. Examination of the relationship between health-promoting behaviors and family characteristics in high school girl students. J Urmia Nurs Midwifery Facul 2015; 13(5):395-403 (Persian).

18. Norouzinia R, Aghabarari M, Kohan M, Karimi M. Health promotion behaviors and its correlation with anxiety and some students' demographic factors of Alborz University of Medical Sciences. J Health Prom Manag 2013; 2(4):3949 (Persian).

19. Motlagh Z, Mazloomy Mahmoodabad S, Momayyezi M. Study of Health-promotion behaviors among university of medical science students. Zahedan J Res Med Sci 2011; 13(4):29-34 (Persian).

20. Senol V, Unalan D, Soyuer F, Argun M. The relationship between health promoting behaviors and quality of life in nursing home residents in Kayseri. J Geriat 2014; 2014:2-10.

21. Mahmoodi H, Asghari-Jafarabadi M, Babazadeh T,
Mohammadi Y, Shirzadi S, Sharifi-Saqezi P, et al. Health promoting behaviors in pregnant women admitted to the prenatal care unit of Imam Khomeini hospital of Saqqez. J Educ Commun Health 2015; 1(4):58-65 (Persian).

22. Mazloomi MZ, Fazelpour S, Askarshahi M. Healthpromoting behaviors and psychosocial well-being of university Shahid Sadoqi Yazd academic staff in Iran. J Ilam Univ Med Sci 2013; 21(3):12-21 (Persian).

23. Kaldi A, Kabiran Eineddin H, Mohagheghi Kamal SH, Rezasoltani P. The evaluation of relationship between health-promoting lifestyle and quality of life (case of study: university of social welfare and rehabilitation sciences students in Tehran). J Iran Soc Dev Stud 2014; 6(4):87-96 (Persian).

24. Mahdavi E, Enayati MS, Neisi A. Review the effectiveness of responsibility training on the self-esteem of high school students. J Soci Psychol 2010; 1(2):117-31 (Persian).

25. Rashno M, Neisi A. Effect of responsibility training to the way reality therapy in reducing female students' identity crisis. J Soci Psychol 2011; 2(1):71-87 (Persian).

26. Mardani HM, Shahraki VA, Moshtagh EZ. Assessment of the effect of educational program based on Trans Theoretical Model (TTM) on physical activity in patients with inflammatory bowel diseases. Sci J Hamdan Univ Med Sci Health Ser 2010; 17(1):39-45 (Persian).

27. Hazrati S, Mardi A, Alijahan R, Nemati A, Tazakori Z, Nezhaddadgar N. Effect of training intervention of nutrition counseling center on feeding behavior in pregnant women referred to health centers in Ardabil city. $6^{\text {th }}$ national congress IRHRC Reproductive and Infertility. Tehran, Iran: Nursing and Midwifery Shahid Beheshti University of Medical Science; 2013 (Persian).

28. Shirbim Z, Sudani M, Shafieabadi A. The effects stress management skills training on mental health scholars of faculty of nursing and midwife college Islamic Azad university of Gachsaran. Andishe Raftar 2008; 2(8):7-18 (Persian). 